\title{
Quasi-Boundary Method for Design Consideration of Resonant DC-DC Converters
}

\author{
Nikolay Hinov
}

\section{check for}

updates

Citation: Hinov, N. Quasi-Boundary Method for Design Consideration of Resonant DC-DC Converters. Energies 2021, 14, 6153. https:// doi.org/10.3390/en14196153

Academic Editor: Byoung Kuk Lee

Received: 29 August 2021

Accepted: 23 September 2021

Published: 27 September 2021

Publisher's Note: MDPI stays neutral with regard to jurisdictional claims in published maps and institutional affiliations.

Copyright: (C) 2021 by the author. Licensee MDPI, Basel, Switzerland. This article is an open access article distributed under the terms and conditions of the Creative Commons Attribution (CC BY) license (https:/ / creativecommons.org/licenses/by/ $4.0 /)$.
Department of Power Electronics, Technical University of Sofia, 1000 Sofia, Bulgaria; hinov@tu-sofia.bg; Tel.: +35-929-652-569

\begin{abstract}
The paper presents a new unified method for designing the two basic types of serial resonant DC-DC converters (series and with a parallel-loaded capacitor). The method is based on the use of a simplified generalized approach for the analysis of this type of power electronic devices. It is characterized by the fact that regardless of the specific operating mode, with a control frequency below or above the resonant of the series resonant circuit to determine the relationship between input and output voltage or current, it is assumed that the converter operates in resonance. In this sense, it is called a quasi-boundary method for analysis and design. The use of the quasiboundary method significantly accelerates and facilitates the design of the considered power circuits, which is very useful for the purposes of engineering practice, as well as in the training of power electronics. The applicability of this approach is proven by the methods of mathematical modeling and computer simulations.
\end{abstract}

Keywords: modeling and simulation; resonant DC-DC converters; design consideration; resonant circuits

\section{Introduction}

Power electronics, and in particular power electronic converters, are one of the most dynamically developing areas of electronics. In view of the increasing penetration of green technologies and the requirements for a circular economy, it is absolutely necessary to repeatedly convert and store electricity with electronic means. In this aspect, it can be considered that power electronics are a key tool for sustainable, efficient and environmentally friendly development of society.

Resonant power converters have become very widespread in both industry and everyday life. They have a number of advantages over other types of power electronic converters such as: the ability to implement "soft" switching, good control characteristics, operation in modes close to short circuit in the load, good energy, size and economic performance, use of parasitic elements such as part of the resonant circuits, etc. [1-10].

On the other hand, power electronic converters of resonant type are characterized by a wide variety of schemes and possible control algorithms, but in the end they are divided into two main groups depending on the type of resonant circuits involved in the formation of output parameters: series (powered by a voltage source) and parallel (powered by a current source). Due to the relatively easier practical implementation of a voltage source than a current source, serial resonant circuits have found wider application in resonant converters $[1,4,6,11,12]$.

In this regard, DC-DC converters realized on the basis of resonant inverters with and without reverse diodes and series resonant circuit are analyzed, modeled, designed and practically implemented for use in various applications in the works of a number of authors [12-18]. The known analyses of this type of power circuits are either very complex and difficult to give a clear idea with a proper physical interpretation of the nature of the ongoing electromagnetic processes, or are associated with a number of assumptions that lead to significant errors. Most often, when deriving the main dependences, the active resistance, which is reduced to the resonant circuit, is neglected [1-5]. Thus, the resonant 
frequency depends only on the values of the resonant elements. On the other hand, in the analysis of a DC-DC converter with a parallel-loaded capacitor, which takes into account the losses in the circuit, as well as the different equivalent circuits as a result of switching between transistors and reverse diodes, design expressions are obtained that are applicable only by using on a computer or other computing equipment [19]. Also available for use are design methodologies developed by manufacturers of components for power electronic devices, which take into account only the basic (first) harmonic of the state variables, and are often combined with graphs from which to select the main parameters $(Q$ factor and detuning) [20-22].

This manuscript proposes a method in which the active resistance in the resonant circuit is taken into account and the resonant current is described by its actual shape. The simplification of the calculation procedures is related to the fact that when performing the analysis it is assumed that regardless of the ratio between the resonant frequency and the switching frequency, the reverse diodes in the inverter part do not work. The reason for the expediency of this assumption is given by the fact that the energy and optimal in terms of using circuit elements modes are in cases where we are dealing with a switching frequency close to the resonant-most often at a frequency ratio in the range of 0.85 to $1.15[1,3,6,9,15,23]$. This assumption makes it possible to obtain convenient expressions through which the design of the considered power schemes is carried out much faster, corresponding to the physical nature of the processes.

The main purpose of this manuscript is based on the application of a new method for analysis of resonant DC-DC converters, to create and verify a simplified design methodology with sufficient accuracy for practical needs to design this class of power electronic devices.

\section{Basic Ratios}

Regardless of the configurations used in the different power circuits, due to the fact that serial resonant DC-DC converters operate at frequencies close to the resonant one, they can ultimately be reduced to two main types: purely serial and with parallel loaded capacitor. The equivalent circuits on which the determination of the main circuit parameters is based are shown in Figure 1, as in the series circuit in the output we have a voltage source $\mathrm{U}_{0}$, and in the parallel loaded capacitor, a current source $\mathrm{I}_{0}[1,5,12,16]$.
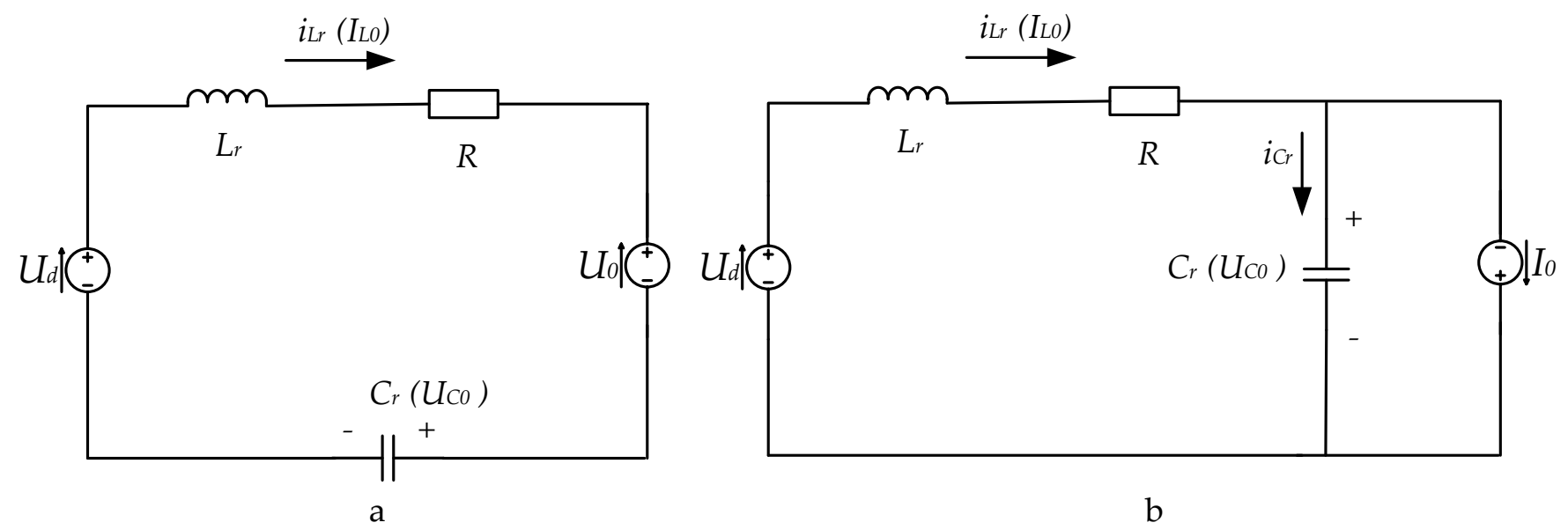

Figure 1. Equivalent circuits of series resonant DC-DC converters (a) series; (b) with a parallel loaded capacitor.

The schemes of Figure 1 contain the same elements: resonant capacitor $C_{r}$, resonant inductance $L_{r}$ and equivalent resistance $R$, which reflects the presence of active resistances in the circuit elements, and $I_{L 0}$ and $U_{C 0}$ are the initial conditions of the state variables, the current through the resonant inductance and voltage on the resonant capacitor. The 
considered series resonant circuits are described by the following differential equation, regarding the capacitor voltage $[1,3,19]$ :

$$
L_{r} C_{r} \frac{d^{2} u_{c}}{d t^{2}}+R C_{r} \frac{d u_{c}}{d t}+u_{c}=u_{S W}
$$

where $u_{\mathrm{sw}}$ is the resultant supply voltage applied to the resonant circuit. It is formed by the sequential operation of the semiconductor switches of the inverter with frequency $f=1 / T$.

In the theory of resonant power converters, more attention is paid to purely series circuits, due to which the basic expressions for the resonant current and voltage on the resonant capacitor for circuits with and without reverse diodes, with and without output rectifier operating in modes with control frequency below and above the resonant $[1,2,5,17,23-26]$. Different parameters were used in performing these analyses. The following are used in the present work: coefficients of hesitation $k$ and detuning $v$. These parameters have been introduced and used in the scientific papers of scientists working in the Department of Power Electronics at the Technical University of Sofia, Bulgaria $[27,28]$.

The essence of the proposed quasi-limit method for analysis and design of series resonant DC-DC converters is that to determine the relationship between input and output voltage and current of the devices it is assumed that they operate at resonance (no operation of the reverse diodes in the inverter), and taking into account the fact that it works with a control frequency different from the resonant joint when calculating the elements of the resonant circuit.

Estimation of the error of the assumption for resonance operation is made on the basis of graphical constructions shown in Figure 2 (at values of the detuning coefficient $v=1.1$ and $v=0.9$ ).

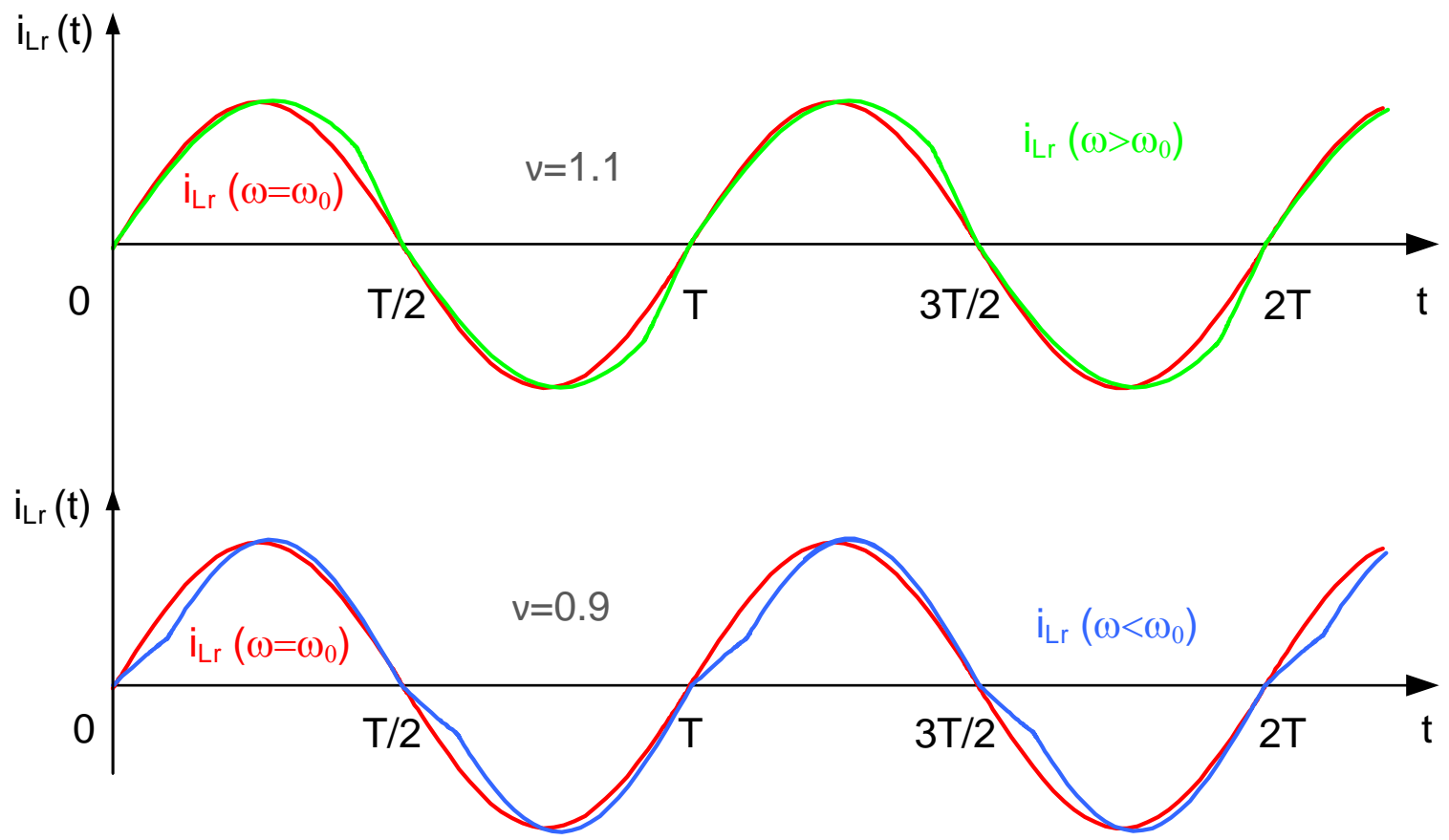

Figure 2. Graphic constructions explaining the difference in the shape of the resonant current when operating with a control frequency equal to the resonant $\left(\omega=\omega_{0}\right)$ and a mode with a control frequency above $\left(\omega>\omega_{0}\right)$ and subresonant $\left(\omega<\omega_{0}\right)$.

The main factors influencing the error are the ratio of the resonant and control frequency and the magnitude of the quality factor of the resonant circuit. The smaller the difference between the switching frequency and the resonant, the smaller the error. The influence of the quality factor is calculated by the coefficient $k$ and at its higher value; 
the active resistance in the resonant circuit decreases (the circuit approaches the ideal) and therefore increases the current flowing through the reverse diodes as the amplitude approaches the current through the transistors. Therefore, when working with large values of $k$, more accurate results are achieved by using the proposed method of analysis and design compared to smaller ones.

The analysis is performed in an established mode, ignoring the imperfections of all circuit elements, except for their active resistances. The expressions for the voltage and current of the resonant capacitor in the series resonant circuit are as follows [7,28]:

$$
\begin{gathered}
u_{C r}(t)=U_{d}-U_{0}-\left(U_{d}-U_{0}+U_{C}(0)\right) e^{-\delta t}\left(\frac{\delta}{\omega_{0}} \sin \omega_{0} t+\cos \omega_{0} t\right)+\frac{I_{L}(0)}{\omega_{0} C_{r}} e^{-\delta t} \sin \omega_{0} t \\
i_{L r}(t)=i_{C r}(t)=\frac{U_{d}-U_{0}+U_{C}(0)}{\omega_{0} L_{r}} e^{-\delta t} \sin \omega_{0} t-I_{L}(0) e^{-\delta t}\left(\frac{\delta}{\omega_{0}} \sin \omega_{0} t-\cos \omega_{0} t\right)
\end{gathered}
$$

To determine the initial values of the state variables based on the condition of periodicity of current and voltage of the resonant capacitor: $i_{L}(0)=-i_{L}\left(\frac{\pi}{\omega}\right)$ and $u_{C}(0)=-u_{C}\left(\frac{\pi}{\omega}\right)$.

The circular control frequency is denoted by $\omega=2 \pi f$.

When operating with a control frequency equal to the resonant one, there is no initial value of the current through the resonant inductance $I_{L}(0)=0$ and thus simplified expressions for the voltage and current of the resonant capacitor are obtained $[7,27,28]$.

The quasi-boundary method for analysis and design of series resonant DC-DC converters will be demonstrated on the basis of a full-bridge transformerless converter shown in Figure 3 in a variant series (Figure 3a) and with a parallel-loaded capacitor (Figure 3b). If it is necessary to use an output transformer or other type of power circuit in the inverter part of the converter (half-bridge, push pool), this is taken into account in the analysis and design using different numerical coefficients, as shown in $[1,3,6,7]$.

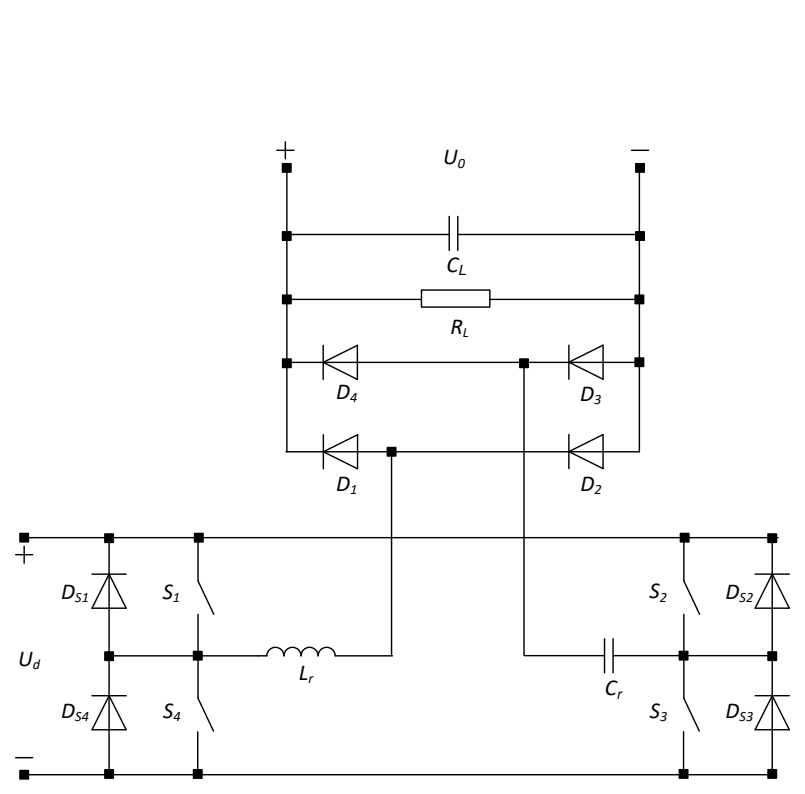

(a)

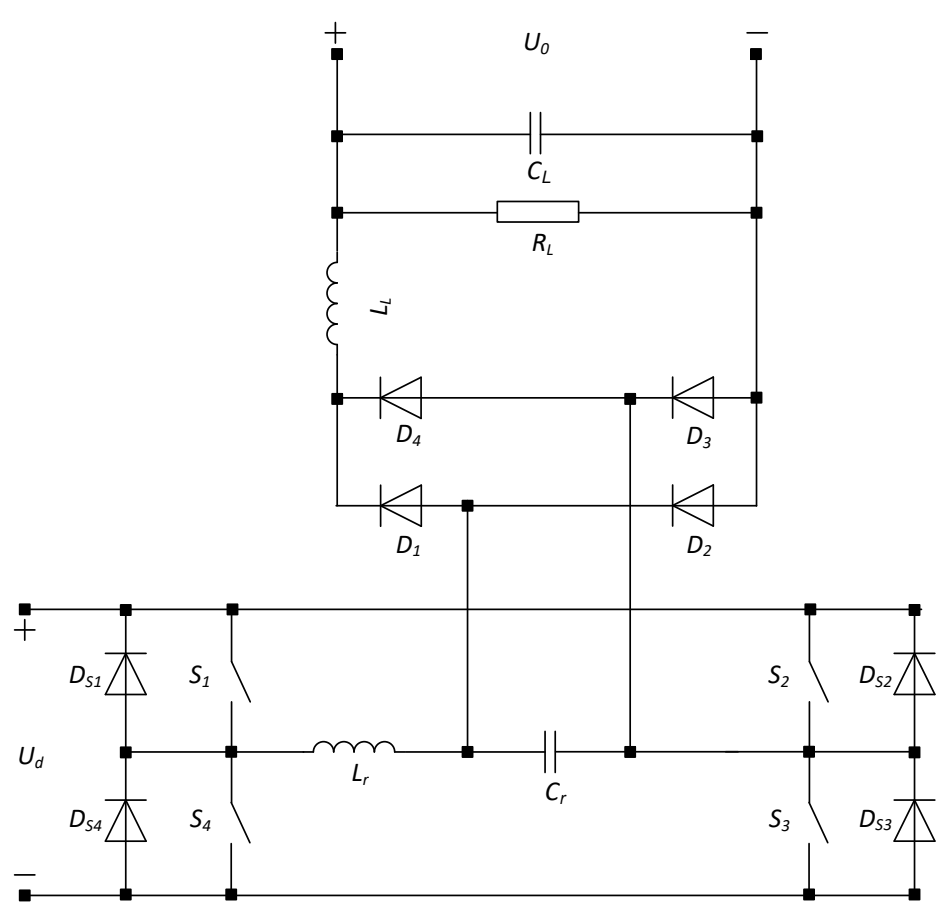

(b)

Figure 3. Resonant DC-DC converters: (a) with a series resonant circuit; (b) with a parallel loaded capacitor.

The following notations are used: $S_{1} \div S_{4}$-controllable switches (transistors) with oneway conductivity; $D S_{1} \div D S_{4}$-reverse diodes, connected in parallel to the switches and with reverse their conductivity; $L_{r}$-resonant inductance, $C_{r}$-resonant capacitor, $D_{1} \div D_{4}$-rectifier diodes; $L_{L}$-output filter inductance; $C_{L}$ —output filter capacitor; $R_{L}$-load resistance. 


\section{Analysis of a Series Resonant DC-DC Converter by the Quasi-Boundary Mode Method}

In the analysis of a series resonant DC-DC converter, the same current flows through the resonant circuit $-i_{C r}=i_{L r}$, and also the inverter current has zero initial condition. Therefore, the expressions for the resonant current and the voltage of the resonant capacitor are as follows $[7,28]$ :

$$
\begin{gathered}
i_{C r}(t)=i_{L r}(t)=\frac{U_{d}-U_{0}+U_{C r}(0)}{\omega_{0} L_{r}} e^{-\delta t} \sin \omega_{0} t \\
u_{C r}(t)=U_{d}-U_{0}-\left(U_{d}-U_{0}+U_{C r}(0)\right) e^{-\delta t}\left(\frac{\delta}{\omega_{0}} \sin \omega_{0} t+\cos \omega_{0} t\right)
\end{gathered}
$$

The initial value of its voltage is determined from the condition for periodicity of the voltage of the resonant capacitor $U_{C}(0)$ :

$$
U_{C}(0)=(2 k-1)\left(U_{d}-U_{0}\right)
$$

where $k=\frac{1}{1-e^{-\delta \frac{\pi}{\omega_{0}}}}$ is a quantity analogous to the quality factor of the series resonant circuit called the coefficient of oscillation $[27,28]$.

In order to obtain design-friendly ratios, it is necessary to present Equation (3) in a normalized form regarding the switching frequency $\omega$. Using Equation (4) and after transformations, the expressions for the resonant current and the voltage of the capacitor are as follows:

$$
\begin{gathered}
i_{L r}(\vartheta)=\frac{2 k\left(U_{d}-U_{0}\right)}{\omega_{0} L_{r}} e^{-\frac{\delta}{\omega} \vartheta} \sin \left(\frac{\pi}{\lambda} \vartheta\right), \\
u_{C r}(\vartheta)=U_{d}-U_{0}-2 k\left(U_{d}-U_{0}\right) e^{-\frac{\delta}{\omega} \vartheta}\left(\frac{\delta}{\omega_{0}} \sin \left(\frac{\pi}{\lambda} \vartheta\right)+\cos \left(\frac{\pi}{\lambda} \vartheta\right)\right)
\end{gathered}
$$

where $\vartheta=\omega t$, and $\lambda=\pi v$, normalized to the switching frequency conduction angle of the transistors.

The basis of any methodology for designing a DC-DC converter is to determine the relationship between the input and output voltage. This is determined taking into account the fact that when working with ideal circuit elements, active power is consumed only in the load resistance. Thus, the average value of the current in the series resonance circuit is equal to the current in the load:

$$
I_{0}=\frac{U_{0}}{R_{L}}=\frac{1}{\pi} \int_{0}^{\lambda} i_{L r}(\vartheta) d \vartheta=(2 k-1)\left(U_{d}-U_{0}\right) 4 f C_{r},
$$

Equation (6) determines this relationship:

$$
U_{0}=U_{d}-\frac{I_{0}}{(2 k-1) 4 f C_{r}}=U_{d}-R_{0} I_{0}
$$

where $R_{0}=\frac{1}{(2 k-1) 4 f C_{r}}$ is the output resistance of the considered converter.

A key point of the analysis and design is the determination of the maximum value of the voltage on the resonant capacitor. The dependence on the operation of the device and the expressions for $u_{\text {Crmax }}$ is valid $[7,28]$ :

$$
U_{C r \max }=U_{C}(0)=(2 k-1)\left(U_{d}-U_{0}\right)=\frac{I_{0}}{4 f C_{r}},
$$

It is evident from the expressions presented above that two coefficients $k$ and $v$ are used in the analysis of the converter. For the purposes of engineering design, it is necessary to know the relationship between the total active resistance (which includes all active resistances in the resonant circuit) in the series resonant circuit $R_{\Sigma}$ and the output resistance 
of the converter $R_{0}$. This dependence is obtained by expressing all the participating quantities in the expression for the initial resistance by means of the coefficients $k$ and $v$.

$$
R_{0}=\frac{1}{(2 k-1) 4 f C_{r}}=\frac{\pi\left(\frac{\ln \left(\frac{k}{k-1}\right)}{\pi}+\frac{\pi}{\ln \left(\frac{k}{k-1}\right)}\right)}{4 v(2 k-1)} R_{\Sigma}=\frac{\pi t g \beta}{2(2 k-1)} R_{\Sigma},
$$

where $\beta$ is the detuning angle of the series resonant circuit, used in the analysis and design of resonant power inverters [28].

With the help of Equation (9) the thus determined dependence between the input and output voltage of the converter becomes a function of the active resistance in the resonant circuit. In this way, Equation (7) acquires the following form, which is very convenient for design purposes:

$$
U_{0}=U_{d}-R_{0} I_{0}=U_{d}-\frac{\pi t g \beta}{2(2 k-1)} R_{\Sigma} I_{0}
$$

With the help of Equation (10) already at the design stage of the device depending on the specific parameters of the used building elements and limits of change of the input voltage with sufficient accuracy for design purposes to determine the output voltage and hence, if necessary, to coordinate with its value by assignment.

All the necessary values for designing a series resonant transducer can be determined by the presented expressions. The summaries used allow them to be used for thyristor circuits as well, in which case only intermittent current mode (value of the coefficient $\lambda$ less than 1) must be operated and thus the necessary circuit time for thyristor recovery must be provided $[7,27,28]$.

\section{Analysis of a Parallel-Loaded Resonant DC-DC Converter by the Quasi-Boundary Mode Method}

In the analysis of the parallel-loaded resonant DC-DC converter, according to the equivalent scheme of Figure 1b, it should be noted that the current through the resonant inductor is formed as the sum of the current of the resonant capacitor and the output current- $i_{L r}=i_{C r}+I_{0}$.

$$
\begin{gathered}
i_{L r}(t)=\frac{U_{d}+U_{C}(0)}{\omega_{0} L_{r}} e^{-\delta t} \sin \omega_{0} t+\left(I_{L}(0)-I_{0}\right) e^{-\delta t}\left(\cos \omega_{0} t-\frac{\delta}{\omega_{0}} \sin \omega_{0} t\right)+I_{0} \\
u_{C r}(t)=U_{d}-\left(U_{d}+U_{C}(0)\right) e^{-\delta t}\left(\frac{\delta}{\omega_{0}} \sin \omega_{0} t+\cos \omega_{0} t\right)+\frac{I_{L}(0)-I_{0}}{\omega_{0} C_{r}} e^{-\delta t} \sin \omega_{0} t-I_{0} R
\end{gathered}
$$

Therefore, when operating in quasi-boundary mode, the expressions for the resonant current and the voltage of the resonant capacitor are:

$$
\begin{gathered}
i_{L r}(t)=\frac{U_{d}+U_{C r}(0)}{\omega_{0} L_{r}} e^{-\delta t} \sin \omega_{0} t-I_{0} e^{-\delta t}\left(\cos \omega_{0} t-\frac{\delta}{\omega_{0}} \sin \omega_{0} t\right)+I_{0} \\
u_{C r}(t)=U_{d}-\left(U_{d}+U_{C r}(0)\right) e^{-\delta t}\left(\frac{\delta}{\omega_{0}} \sin \omega_{0} t+\cos \omega_{0} t\right)-\frac{I_{0}}{\omega_{0} C_{r}} e^{-\delta t} \sin \omega_{0} t-I_{0} R
\end{gathered}
$$

From the condition for periodicity of the voltage of the resonant capacitor its initial value is determined; $U_{\mathrm{Cr}}(0)$ :

$$
U_{C r}(0)=(2 k-1) U_{d}
$$

In order to find expressions convenient for design, it is necessary to present (12) in a normalized form with regarding to the switching frequency $\omega$. Using (13) and after transformations, the expressions for the resonant inductance current and the capacitor voltage are as follows:

$$
\begin{gathered}
i_{L r}(\vartheta)=\frac{2 k U_{d}}{\omega_{0} L_{r}} e^{-\frac{\delta}{\omega} \vartheta} \sin \left(\frac{\pi}{\lambda} \vartheta\right)-I_{0} e^{-\frac{\delta}{\omega} \vartheta}\left(\cos \left(\frac{\pi}{\lambda} \vartheta\right)-\frac{\delta}{\omega_{0}} \sin \left(\frac{\pi}{\lambda} \vartheta\right)\right)+I_{0} \\
u_{C r}(\vartheta)=U_{d}-2 k U_{d} e^{-\frac{\delta}{\omega} \vartheta}\left(\frac{\delta}{\omega_{0}} \sin \left(\frac{\pi}{\lambda} \vartheta\right)+\cos \left(\frac{\pi}{\lambda} \vartheta\right)\right)-\frac{I_{0}}{\omega_{0} C_{r}} e^{-\frac{\delta}{\omega} \vartheta} \sin \left(\frac{\pi}{\lambda} \vartheta\right)-I_{0} R
\end{gathered}
$$

To create a methodology for designing a resonant DC-DC converter with a parallelloaded capacitor, it is necessary to determine the relationship between the input and 
output current of the converter. When working with ideal building blocks, active power is consumed only in the load resistance. In this case, the average value of the resonant inductance current is equal to the input current consumed by the power supply:

$$
I_{d}=\frac{1}{\pi} \int_{0}^{\lambda} i_{L r}(\vartheta) d \vartheta=(2 k-1) U_{d} 4 f C_{r}+I_{0},
$$

Through Equation (15) is the connection between the input and output current of the converter:

$$
I_{0}=I_{d}-(2 k-1) 4 f C_{r} U_{d}=I_{d}-\frac{U_{d}}{R_{0}},
$$

where $R_{0}=\frac{1}{(2 k-1) 4 f C_{r}}$ is the output resistance of a series resonant converter with a parallel loaded capacitor.

In order to create a methodology for designing the considered type of converters, it is necessary to determine the maximum value of the voltage on the resonant capacitor. The following dependence is valid from the principle of operation of the power scheme:

$$
U_{C r \max }=U_{C}(0)=(2 k-1) U_{d}=\frac{I_{d}-I_{0}}{4 f C_{r}},
$$

Since Equations (7) and (16) involve identical quantities, the expression of the output resistance for both types of converters is done with the same Equation (9).

\section{Design Consideration}

Usually, when designing DC-DC converters, the following parameters are set: output power, the values of the input and output voltage and of the output current (nominal and with their limits of variation). The requirements related to electromagnetic compatibility, mass and size of the devices and efficiency determine the operating frequency. Below is an example sequence for determining the most important parameters needed for the design of the considered devices.

\subsection{Serial DC-DC Converter}

A number of studies presented in $[1-3,7,26,28]$ give the relationship between the converted power and the current and voltage loads of the building elements. In this way, depending on the design input, it is possible to estimate the component loads. On this basis, the loss resistances that form $R_{\Sigma}$ are determined. Figure 4 shows the dependence (10) as a percentage of the value of the input voltage. The graphs are given for parameters of the values of the load current and of the coefficients $k$ and $R_{\Sigma}$. It is recommended that the presented characteristics be used for the initial determination of the output voltage value. In addition, they are useful for quickly checking whether the setpoint parameters can be achieved by directly connecting the load without using an inverter transformer. On the other hand, a value of the coefficient $v$ should be chosen, by which to fix the specific operating mode (most often for a number of reasons with the frequency of superresonance control).

The graphical constructions of Figure 4 show an interesting dependence of the output voltage: it practically does not depend on the coefficient $k$, and its value decreases with increasing load current and the active resistance of the series resonant circuit. The operation of an inverter transformer is reflected in Equation (10), as the output voltage is reduced to the equivalent circuit by the transformation coefficient, and the resistances of its windings are added to the value of $R_{\Sigma}$.

In this way, the following design sequence is obtained:

1. The value of the coefficient $\mathrm{k}$ is determined by Equation (8) at a given maximum value of the output current and a selected load of the resonant capacitor. Thus found, 
it will be used in determining the other quantities. The corresponding value of the resonant capacitor $C_{r}$ is determined from the same expression.

2. From Equation (10) the value of the load voltage is determined, using the already determined coefficients.

3. The attenuation factor and the resonant inductance are determined from the following dependence:

$$
\delta=\frac{R_{\Sigma}}{2 L_{r}}=\frac{\omega_{0}}{\pi} \ln \left(\frac{k}{k-1}\right)=\frac{\omega}{\pi v} \ln \left(\frac{k}{k-1}\right)
$$

4. The maximum value of the current through the transistors is determined by the maximum value of the voltage on the resonant capacitor:

$$
I_{\max }=U_{C r \max } \omega C_{r}
$$

5. Assuming a sinusoidal shape of the resonant current, the value of the output capacitor is determined by [7]:

$$
C_{L}=\frac{2 \lambda}{\omega \Delta U_{0}}\left(\frac{\sqrt{1-\left(\frac{I_{0}}{I_{\max }}\right)^{2}}}{\frac{I_{0}}{I_{\max }}}-\arccos \frac{I_{0}}{I_{\max }}\right) I_{0},
$$

where $\Delta U_{0}$ are the ripple of the output voltage. In the described way, with the presented several steps, the engineering design of the converter is realized.
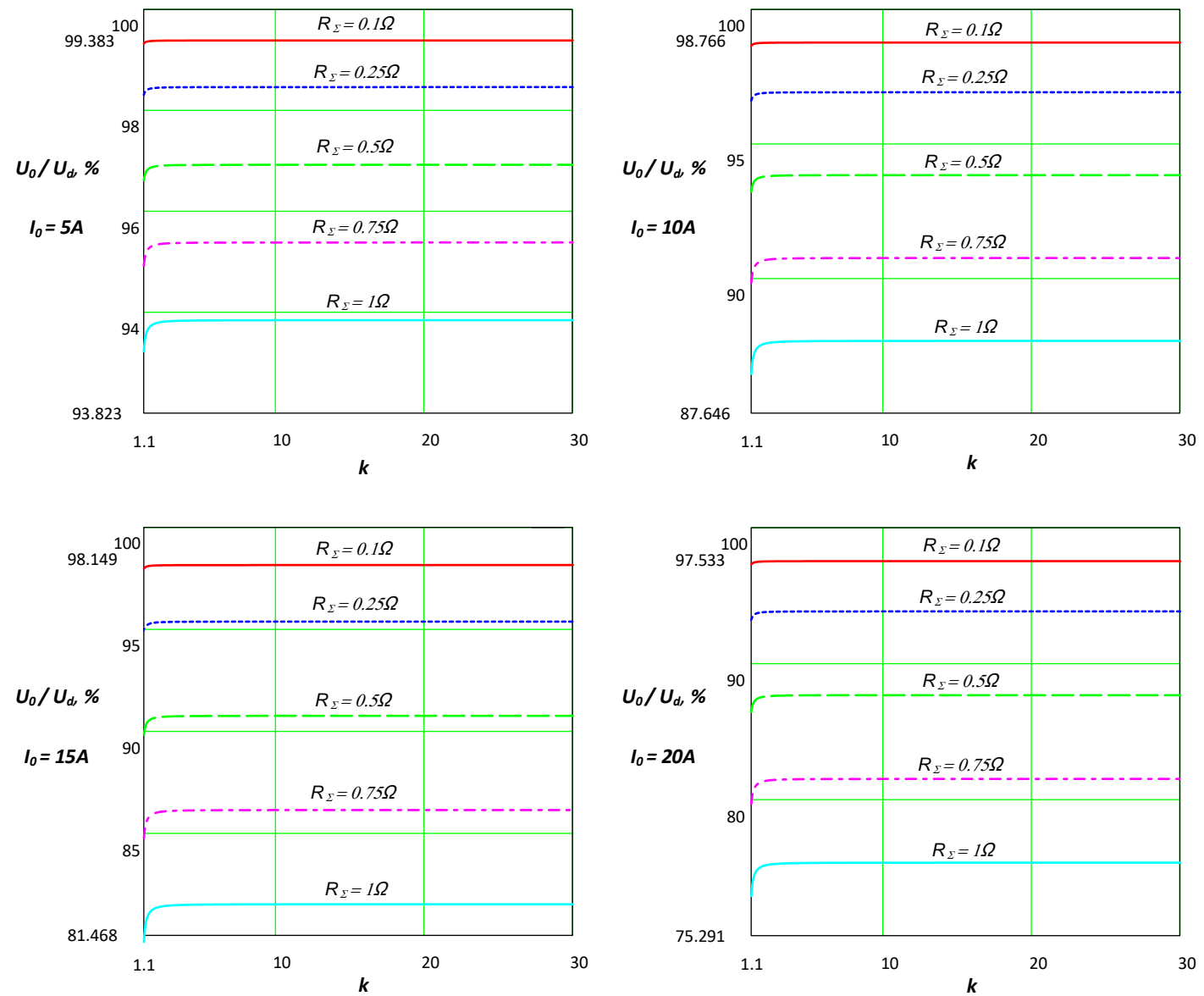

Figure 4. Dependence of the output on the input voltage of a series resonant DC-DC converter at different values of the parameters $R_{\Sigma}$ and the load current $I_{0}$. 


\subsection{Resonant DC-DC Converter with a Parallel-Loaded Capacitor}

The design of the resonant converter with a parallel loaded capacitor proceeds in a similar way to that of the series one. Again, the output parameters, the nominal value of the input and output voltage with the respective variation limits and the minimum and maximum value of the load current are set as input parameters, and also the operating frequency of the converter is selected or set.

Based on the assessment of the loads of the building elements, their active resistances, which participate in $R_{\Sigma}$, are determined. Figure 5 shows the dependence (Equation (16)) as a percentage of the value of the input current for different values of the supply voltage (respectively the power to be converted) and when the coefficient $k$ and $R_{\Sigma}$ change. These characteristics are used to initially determine the output current and to quickly check whether the setpoint parameters can be achieved without the need for coordination.
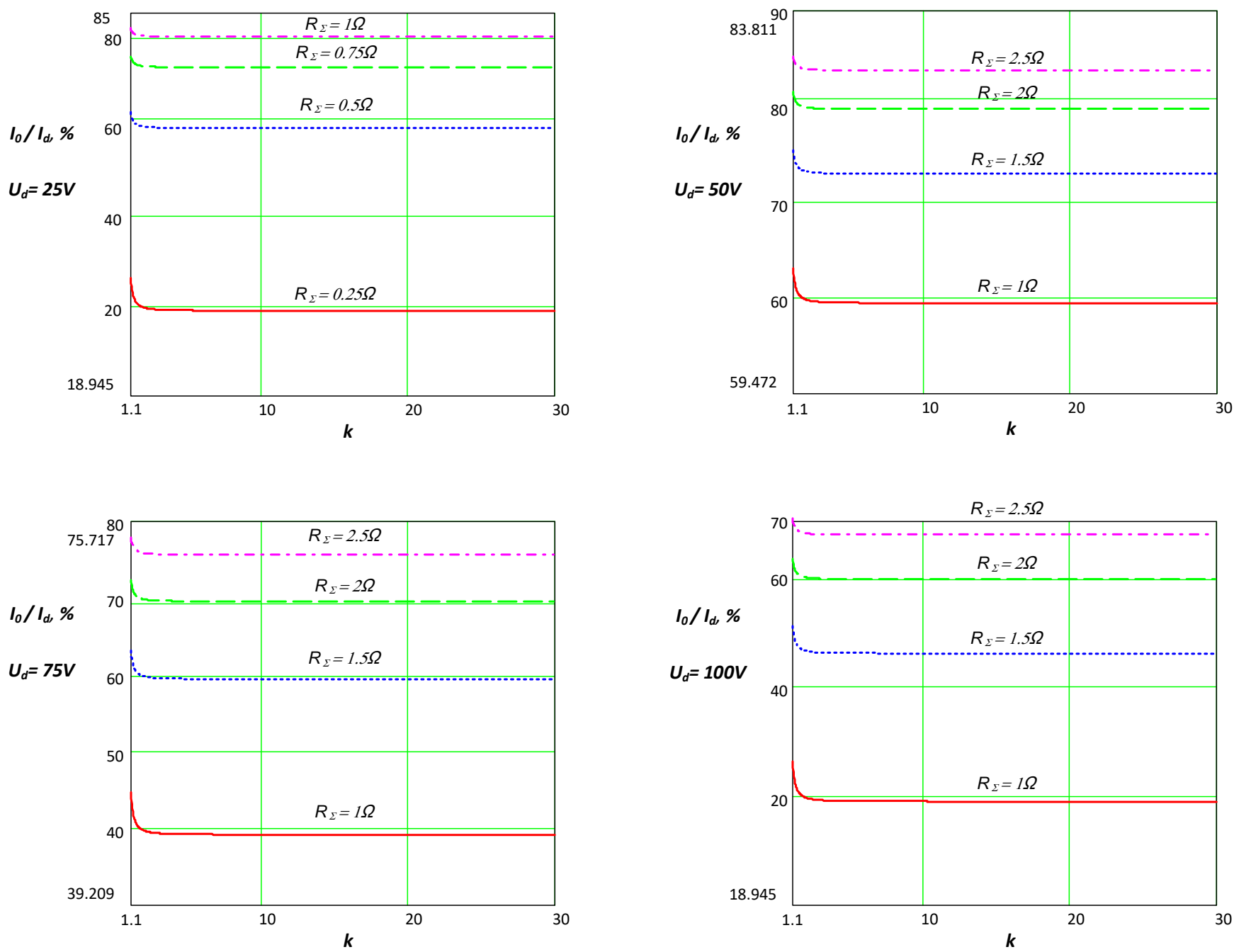

Figure 5. Dependence of the output current on the input current resonant converter with a parallel loaded capacitor at different values of the parameters $R_{\Sigma}$ and the input voltage $U_{d}$.

The constructions of Figure 5 show a similar dependence of the output current as in the series circuit: it practically does not change with the change of the coefficient $k$, but decreases significantly with increasing supply voltage and decreases the active resistance of the resonant circuit. The use of an output transformer will not affect the nature of these dependencies, and the resistances of its windings are added to the value $R_{\Sigma}$.

In this regard, the design is carried out in the following main steps: 
1. From Equation (17) at a set maximum load current, selected supply voltage and load of the resonant capacitor, the required value of the coefficient $\mathrm{k}$ is determined, for the needs of the design.

2. By Equation (16) the value of the output current is obtained, at the thus selected coefficients and conversion power.

3. From the dependence (Equation (18)) the attenuation coefficient and respectively the resonant inductance are determined.

4. The value of the resonant capacitor $\mathrm{Cr}$ is determined by:

$$
C_{r}=\frac{1}{L_{r}\left(\omega_{0}^{2}+\delta^{2}\right)}
$$

5. The maximum value of the current through the transistors is determined by the maximum value of the voltage across the resonant capacitor and the operating frequency by means of Equation (19).

6. Assuming a sinusoidal shape of the resonant current, the value of the filter elements is determined depending on the required smoothing coefficient as in the case of main voltage rectifiers $[5,6]$.

These few steps are the basis for determining the main quantities involved in the design of the converter in question.

\section{Verification of the Design Methodology}

The validity of the proposed methods will be verified by designing two examples of a series resonant DC-DC converter (Figure 3a) and a resonant DC-DC converter with a parallel-loaded capacitor (Figure 3b), respectively.

Table 1 shows the output data used to design a serial DC-DC converter. In addition, a comparison was made between the design data and the results obtained with the means of mathematical modeling (Matlab/Simulink) and computer simulations (LTspice).

Table 1. Initial data for design of serial DC-DC converter and results obtained by modeling and simulations.

\begin{tabular}{ccc}
\hline Initial Data & Mathematical Modeling & Computer Simulation \\
\hline$U_{d}=110 \mathrm{~V}$ & $U_{d}=110 \mathrm{~V}$ & $U_{d}=110 \mathrm{~V}$ \\
$U_{0}=102.597 \mathrm{~V}$ & $U_{0}=102.45 \mathrm{~V}$ & $U_{0}=102.68 \mathrm{~V}$ \\
$\Delta U_{0}=100 \mathrm{mV}$ & $\Delta U_{0}=48.5 \mathrm{mV}$ & $\Delta U_{0}=46.5 \mathrm{mV}$ \\
$I_{0}=20 \mathrm{~A}$ & $I_{0}=20.386 \mathrm{~A}$ & $I_{0}=20.43 \mathrm{~A}$ \\
$U_{C r \max }=214.687 \mathrm{~V}$ & $U_{C r \max }=219.3 \mathrm{~V}$ & $U_{C r \max }=220.95 \mathrm{~V}$ \\
$I_{m}=31.416 \mathrm{~A}$ & $I_{m}=31.06 \mathrm{~A}$ & $I_{m}=30.96 \mathrm{~A}$ \\
\hline
\end{tabular}

During the design, an operating frequency of $200 \mathrm{kHz}$ was selected, with operation in the mode with supersonic control frequency $(v=1.1)$, value of the coefficient $k=15$ and $R_{\Sigma}=0.3 \Omega$. As a result of the use of the methodology, the following values of the circuit elements were obtained: resonant inductance $L_{r}=5.979 \mu \mathrm{H}$; resonant capacitor $C_{r}=116.4 \mathrm{nF}$; load resistance (at maximum current) $R_{L}=5 \Omega$; filter capacitor $C_{L}=20 \mu \mathrm{F}$.

From the data presented in Table 1 it is found that by using the presented design methodology a very good accuracy has been achieved; the largest difference between the values calculated and obtained from numerical experiments is less than $2.5 \%$. The deviations are due not only to the assumptions made in the analysis of the schemes, but also to the differences in the models used for the verification. Taking into account that in the construction of power electronic devices the building elements have a tolerance of their parameters usually around and above $20 \%$, the proposed methodology gives excellent results without the use of complex computational procedures.

Table 2 shows the output data used to design a series DC-DC converter with a parallelloaded capacitor. Again, a comparison was made between the design data and the results obtained with the means of mathematical modeling (Matlab/Simulink) and computer simulations (LTspice). 
Table 2. Initial data for design of a resonant DC-DC converter with a parallel-loaded capacitor and results obtained by modeling and simulations.

\begin{tabular}{ccc}
\hline Initial Data & Mathematical Modeling & Computer Simulation \\
\hline$U_{d}=30 \mathrm{~V}$ & $U_{d}=30 \mathrm{~V}$ & $U_{d}=30 \mathrm{~V}$ \\
$I_{0}=10 \mathrm{~A}$ & $I_{0}=10.032 \mathrm{~A}$ & $I_{0}=10.05 \mathrm{~A}$ \\
$\Delta U_{0}=10 \mathrm{mV}$ & $\Delta U_{0}=5 \mathrm{mV}$ & $\Delta U_{0}=6.5 \mathrm{mV}$ \\
$U_{0}=60 \mathrm{~V}$ & $U_{0}=60.2 \mathrm{~V}$ & $U_{0}=60.32 \mathrm{~V}$ \\
$U_{C r \max }=105 \mathrm{~V}$ & $U_{C r \max }=102.3 \mathrm{~V}$ & $U_{C r \max }=101.9 \mathrm{~V}$ \\
$I_{m}=52.84 \mathrm{~A}$ & $I_{m}=51.05 \mathrm{~A}$ & $I_{m}=51.06 \mathrm{~A}$ \\
\hline
\end{tabular}

During the design, an operating frequency of $200 \mathrm{kHz}$ was selected, with operation in a mode with supersonic control frequency $(v=1.1)$, value of the coefficient $k=2.25$ and $R_{\Sigma}=0.3 \Omega$. As a result of the use of the methodology, the following values of the circuit elements were obtained: resonant inductance $L_{r}=1.82 \mu \mathrm{H}$; resonant capacitor $C_{r}=412.354 \mathrm{nF}$; load resistance (at maximum current) $R_{L}=6 \Omega$; filter capacitor $C_{L}=20 \mu \mathrm{F}$ and filter inductor $L_{L}=100 \mu \mathrm{H}$.

From the presented data it is established that the methodology gives a very good match and is appropriate to determine the circuit elements of the studied power electronic device.

\section{Discussion}

The presented results confirm the validity and efficiency of the quasi-boundary method for analysis and design of serial resonant DC-DC converters. The reading of the active resistances in the resonant circuit is useful in view of the use of elements with characteristics different from the ideal ones and especially in the case of devices with low power (below $100 \mathrm{~W}$ ). On the other hand, this approach is also applicable to other types of resonant power converters, which operate in modes close to resonance, as in this way basic relations are obtained, which makes it very easy and convenient to determine the circuit elements. This is important in order to improve both the learning process in power electronics and in engineering practice; that is, to achieve an optimal solution to a particular problem using fast and innovative design methods. A natural development of this method is its application to resonant transducers with complex output circuits in order to obtain a matching or galvanic separation between the input and output such as LLC and LCC. The disadvantages of the proposed approach are mainly related to the increase of the error in operating modes with control frequencies with more than $20 \%$ difference from the resonant one.

\section{Conclusions}

The manuscript proposes a new approach to the analysis and design of serial resonant DC-DC converters, based on the use of expressions valid for operation with a control frequency equal to the resonant. The development and improvement of this method involves the combination of mathematical modeling tools, basic relationships for determining the initial values of circuit elements, based on the analysis of established processes in the circuit, and application of artificial intelligence techniques for the final finding of optimal values of building elements and for control synthesis. This is shown in [29] by using model-based optimization, which realizes, by creating and verifying a model of the converter, a reference (set) trajectory of the parameter to be optimized and the search for a minimum deviation of the parameter from the set optimal trajectory by the method of the smallest squares. Thus, the combination of classical methods for analysis and design and modern means of computational mathematics and modeling eliminates one of the biggest weaknesses in the analysis and design of power electronic devices: the derivation of basic dependencies to be performed with a fixed mode of operation, without taking into account the duration and nature of the transitional processes.

Unlike other methods for analysis and design, the quasi-boundary method takes into account the active resistances in the resonant circuit, which, when using simplified depen- 
dencies, achieves a more precise determination of the circuit elements. This method does not deny, but instead complements and develops the classical methods of design, assuming their combination with modern means of applied mathematics and mathematical modeling.

Funding: This research was funded by European Regional Development Fund, within the Operational Programme "Science and Education for Smart Growth 2014-2020" under the Project CoE "National center of mechatronics and clean technologies", grant number BG05M2OP001-1.001-0008 and the APC was funded by European Regional Development Fund.

Institutional Review Board Statement: Not applicable.

Data Availability Statement: Not applicable.

Acknowledgments: The research was supported by the European Regional Development Fund within the Operational Programme "Science and Education for Smart Growth 2014-2020" under the Project CoE "National center of mechatronics and clean technologies" BG05M2OP001-1.001-0008.

Conflicts of Interest: The author declare no conflict of interest.

\section{References}

1. Mohan, N.; Undeland, T.M.; Robbins, W.P. Power Electronics-Converters, Applications, and Design, 3rd ed.; John Wiley \& Sons: Hoboken, NJ, USA, 2003.

2. Kazimierczuk, M.K.; Czarkowski, D. Resonant Power Converters, 2nd ed.; IEEE Press John Wiley \& Sons: New York, NY, USA, 2011; pp. 1-595, ISBN 978-0-470-90538-8.

3. Dokić, B.L.; Blanuša, B. Power Electronics Converters and Regulators, 3rd ed.; Springer International Publishing: Cham, Switzerland, 2015; ISBN 978-3-319-09401-4.

4. Rashid, M.H. Power Electronics Handbook: Devices, Circuits, and Applications; Academic Press: Cambridge, MA, USA, 2007.

5. Erickson, R.W.; Maksimovic, D. Fundamentals of Power Electronics, 2nd ed.; Kluwer Academic Publishers Group: London, UK, 2001.

6. Zinoviev, G. Fundamentals of Power Electronics-Part II; Novosibirsk State University: Novosibirsk, Russia, 2004. (In Russian)

7. Belov, G.A. High-Frequency Thyristor-Transistor DC-DC Converters; Energoatomizdat: Moscow, Russia, 1987. (In Russian)

8. Sidorov, V.; Chub, A.; Vinnikov, D. Performance Improvement of PWM Control Methods for Voltage Step-Down in Series Resonant DC-DC Converters. Energies 2020, 13, 4569. [CrossRef]

9. Zhang, W.; Mao, P.; Liu, Y. Small-Signal Modeling of Series Resonant Converter. In Proceedings of the 7th International Conference on Power Electronics and Drive Systems, Bangkok, Thailand, 27-30 November 2007; pp. 1466-1470. [CrossRef]

10. Kato, H.; Drabek, P. Comparative analysis of full bridge and half bridge current resonant DC-DC converter. In Proceedings of the 2011 IEEE 33rd International Telecommunications Energy Conference (INTELEC), Amsterdam, The Netherlands, 9-13 October 2011; pp. 1-6. [CrossRef]

11. Maixe, J.; de Vicuna, L.G.; Pique, R. Current-source resonant DC-DC converter. In Proceedings of the IECON94-20th Annual Conference of IEEE Industrial Electronics, Bologna, Italy, 5-9 September 1994; pp. 153-158. [CrossRef]

12. Mikhalchenko, S.G.; Stolyarova, A.A. Analysis of resonant converters at wide input voltage range. In Proceedings of the 2016 17th International Conference of Young Specialists on Micro/Nanotechnologies and Electron Devices (EDM), Erlagol (Altai Republic) Russia, 30 June-4 July 2016; pp. 512-517. [CrossRef]

13. Andreiciks, A.; Steiks, I.; Krievs, O. Design of resonant DC/DC converter for fuel cell application. In Proceedings of the 2012 13th Biennial Baltic Electronics Conference, Tallinn, Estonia, 3-5 October 2012; pp. 219-222. [CrossRef]

14. Hahn, C.; Lehn, P. Modelling and Control Design for a High Power Resonant DC-DC Converter. In Proceedings of the 2012 Sixth IEEE/PES Transmission and Distribution: Latin America Conference and Exposition (T\&D-LA), Montevideo, Uruguay, 3-5 September 2012; pp. 1-6. [CrossRef]

15. Mikolajewski, M. Resonant DC/DC converters with a transformer regulated synchronous rectifier. In Proceedings of the IEEE International Symposium on Industrial Electronics, Warsaw, Poland, 17 June 1996; Volume 2, pp. 713-718. [CrossRef]

16. Zhengzhang, S.; Yun, G.; Pu, S. Parameter Design Method of a Series-parallel Resonant Converter. In Proceedings of the 2018 IEEE 4th Information Technology and Mechatronics Engineering Conference (ITOEC), Chongqing, China, 14-16 December 2018; pp. 1024-1027. [CrossRef]

17. Steigerwald, R.L. Practical design methodologies for load resonant converters operating above resonance. In Proceedings of the Fourteenth International Telecommunications Energy Conference INTELEC, Washington, DC, USA, 4-8 October 1992; pp. 172-179. [CrossRef]

18. Chin, Y.; Lee, F.C.Y. Constant-frequency parallel-resonant converter. IEEE Trans. Ind. Appl. 1989, 25, 133-142. [CrossRef]

19. Lin, Y.-L. Resonant DC/DC Converters: Modeling, Control Strategies, Simulation, and Experimental Studies. Ph.D. Thesis, Rochester Institute of Technology, Rochester, NY, USA, 1986. Available online: https://scholarworks.rit.edu/theses/6515/ (accessed on 6 February 2014).

20. Survey of Resonant Converter Topologies-Texas Instruments. Available online: https://www.ti.com/seclit/mL/slup376/slup3 76.pdf (accessed on 18 April 2018). 
21. LLC Resonant Converter STMicroelectronics. Available online: https://www.st.com/en/applications / power-supplies-andconverters/llc-resonant-converter.html (accessed on 28 November 2016).

22. Microchips 200w dc/dc llc Resonant Converter Reference Design. Available online: https://www.microchip.com/en-us/ development-tool/dc-dc-llc-resonant-converter (accessed on 20 August 2019).

23. Bhat, A.K.S. Analysis and design of a series-parallel resonant converter with capacitive output filter. IEEE Trans. Ind. Appl. 1991, 27, 523-530. [CrossRef]

24. Johnson, S.D.; Erickson, R.W. Steady-state analysis and design of the parallel resonant converter. IEEE Trans. Power Electron 1988, 3, 93-104. [CrossRef]

25. Kang, Y.-G.; Upadhyay, A.K. Analysis and design of a half-bridge parallel resonant converter. IEEE Trans. Power Electron 1988, 3 , 254-265. [CrossRef]

26. King, R.J.; Stuart, T.A. Modeling the Full-Bridge Series-Resonant Power Converter. IEEE Trans. Aerosp. Electron. Syst. 1982, 4, 449-459. [CrossRef]

27. Popov, E. Analysis, Modeling and Design of Converter Units (Computer-Aided Design of Power Electronic Circuits); Technical University Printing House: Sofia, Bulgaria, 2005. (In Bulgria)

28. Hinov, N. New Method for Designing Serial Resonant Power Converters. AIP Conf. Proc. 2017, 1910, 060019-1-060019-6, ISBN 978-0-7354-1602-4.

29. Hinov, N.; Gilev, B.; Hranov, T. Model-Based Optimization of an LLC-Resonant DC-DC Converter. Electronics 2019, 8, 799. [CrossRef] 